\title{
The effect of yoga on sleep quality and insomnia in women with sleep problems: a systematic review and meta-analysis
}

\author{
Wei-Li Wang ${ }^{1}$, Kuang-Huei Chen ${ }^{1}$, Ying-Chieh Pan', Szu-Nian Yang ${ }^{2}$ and Yuan-Yu Chan ${ }^{1,3^{*}}$
}

\begin{abstract}
Background: To examine the effectiveness and safety of yoga of women with sleep problems by performing a systematic review and meta-analysis.
\end{abstract}

Methods: Medline/PubMed, ClinicalKey, ScienceDirect, Embase, PsycINFO, and the Cochrane Library were searched throughout the month of June, 2019. Randomized controlled trials comparing yoga groups with control groups in women with sleep problems were included. Two reviewers independently evaluated risk of bias by using the risk of bias tool suggested by the Cochrane Collaboration for programming and conducting systematic reviews and metaanalyses. The main outcome measure was sleep quality or the severity of insomnia, which was measured using subjective instruments, such as the Pittsburgh Sleep Quality Index (PSQI), Insomnia Severity Index (ISI), or objective instruments such as polysomnography, actigraphy, and safety of the intervention. For each outcome, a standardized mean difference (SMD) and confidence intervals (Cls) of 95\% were determined.

Results: Nineteen studies in this systematic review included 1832 participants. The meta-analysis of the combined data conducted according to Comprehensive Meta-Analysis showed a significant improvement in sleep (SMD =$0.327,95 \% \mathrm{Cl}=-0.506$ to $-0.148, P<0.001$ ). Meta-analyses revealed positive effects of yoga using PSQI scores in 16 randomized control trials (RCTs), compared with the control group in improving sleep quality among women using PSQI (SMD $=-0.54 ; 95 \% \mathrm{Cl}=-0.89$ to $-0.19 ; P=0.003)$. However, three RCTs revealed no effects of yoga compared to the control group in reducing insomnia among women using ISI (SMD $=-0.13 ; 95 \% \mathrm{Cl}=-0.74$ to $0.48 ; P=0.69$ ). Seven RCTs revealed no evidence for effects of yoga compared with the control group in improving sleep quality for women with breast cancer using PSQI (SMD $=-0.15 ; 95 \% \mathrm{Cl}=-0.31$ to $0.01 ; P=0.5)$. Four RCTs revealed no evidence for the effects of yoga compared with the control group in improving the sleep quality for peri/ postmenopausal women using PSQI (SMD $=-0.31 ; 95 \% \mathrm{Cl}=-0.95$ to $0.33 ; P=0.34)$. Yoga was not associated with any serious adverse events.

\footnotetext{
* Correspondence: xaviorchan@gmail.com

'Department of Psychiatry, Taoyuan Armed Forces General Hospital, Taoyuan,

Taiwan

${ }^{3}$ Department of Psychology, Chung Yuan Christian University, Taoyuan,

Taiwan

Full list of author information is available at the end of the article
}

(c) The Author(s). 2020 Open Access This article is licensed under a Creative Commons Attribution 4.0 International License, which permits use, sharing, adaptation, distribution and reproduction in any medium or format, as long as you give appropriate credit to the original author(s) and the source, provide a link to the Creative Commons licence, and indicate if changes were made. The images or other third party material in this article are included in the article's Creative Commons licence, unless indicated otherwise in a credit line to the material. If material is not included in the article's Creative Commons licence and your intended use is not permitted by statutory regulation or exceeds the permitted use, you will need to obtain permission directly from the copyright holder. To view a copy of this licence, visit http://creativecommons.org/licenses/by/4.0/ The Creative Commons Public Domain Dedication waiver (http://creativecommons.org/publicdomain/zero/1.0/) applies to the data made available in this article, unless otherwise stated in a credit line to the data. 
(Continued from previous page)

Discussion: This systematic review and meta-analysis demonstrated that yoga intervention in women can be beneficial when compared to non-active control conditions in term of managing sleep problems. The moderator analyses suggest that participants in the non-breast cancer subgroup and participants in the non-peri/ postmenopausal subgroup were associated with greater benefits, with a direct correlation of total class time with quality of sleep among other related benefits.

Keywords: Yoga, Sleep quality, Insomnia, Women, Complementary and alternative medicine, Meta-analysis, Review

\section{Background}

Sleep problems are one of the most common medical complaints. Lack of sleep is associated with significantly decreased work performance, impaired daytime function, and increased health care costs [1]. Sex-based differences in sleep problems have been widely published and discussed across sleep articles. Insomnia is approximately 1.41 times more common in women than in men [2]. Female populations at certain stages in their life span may be more vulnerable to insomnia. In these stages, hormonal changes associated with hormones, such as follicle-stimulating hormones (FSHs), luteinizing hormones (LHs), and progesterone, may play an important role in influencing women's sleep construction [3] during adolescence [4], pregnancy and postpartum [5] or menopause [6]. Several behavioral, psychological and pharmacological treatments are available for insomnia, however, their efficacy varies considerably. The evidence of efficacy for cognitive behavior therapy is now well established in many reviews $[7,8]$, but availability remains poor. Pharmacotherapy remains the most common treatment [9], although hypnotics have been associated with many side effects, such as drowsiness, cognitive impairment, dependence, tolerance and poor long term efficacy [10].

Yoga has been widely adapted in the modern Eastern and Western hemispheres in a variety of ways. Yoga is an ancient form of exercise that focuses on strength, flexibility, and breathing to boost physical, mental and spiritual health [11]. There are many different styles of yoga, such as Tibetan, Iyengar, and Hatha Yoga. Some styles are more vigorous than others, whereas some may have different areas of emphasis, such as posture or breathing. The main components of yoga in Europe or America are mostly associated with physical posture (Asana) and breathing control (Pranayama) and meditation (Dhyana) [11]. A trial in yoga for persistent fatigue breast cancer survivors showed yoga is safe and effective at improving fatigue severity, depressive moods, and sleep quality [12]. Yoga is also characterized as a mindful mode of physical activity. Mindfulness, as an important component of yoga, improves sleep disturbance by increasing melatonin levels, reducing hyperarousal, and addressing stress related cardiac and respiratory abnormalities [13].

The term "sleep quality" is commonly used in sleep medicine. In 1989, Buysse et al. referred to sleep quality as a "complex phenomenon that is difficult to define and measure objectively" [14]. Good sleep quality is associated with better health, less daytime sleepiness, greater well-being and better psychological functioning [15]. Recently, sleep quality is defined as one's satisfaction of the sleep experience, integrating aspects of sleep initiation, sleep maintenance, sleep quantity, and refreshment upon awakening [16]. The National Sleep Foundation (NSF) released the key indicators of good sleep quality, as established by a panel of experts. They include increase in sleeping time while in bed (at least $85 \%$ of the total time), falling asleep in $30 \mathrm{~min}$ or less, waking up no more than once per night and being awake for $20 \mathrm{~min}$ or less after initially falling asleep. However, there was less or no consensus regarding sleep architecture or naprelated variables as elements of good sleep quality [17]. Poor sleep quality is one of the defining features of chronic insomnia [18]. Although recent systematic reviews and meta-analyses have assessed the efficacy and safety of yoga in specific groups of women, such as those with prenatal depression [19] and primary dysmenorrhea [20] in different stages, evidence for the efficacy of yoga in improving sleep quality and insomnia of women has not yet been systematically assessed. Thus, the aim of this review was to systematically evaluate and perform a meta-analysis of the available data on the efficacy and safety of yoga in terms of improving sleep quality and insomnia in women.

\section{Methods}

Before beginning the review, we followed the checklist for systematic reviews in concurrence with the preferred reporting items for systematic reviews and meta-analyses (PRISMA) guidelines [21] and suggestions by the Cochrane Collaboration for programming and conducting systematic reviews and meta-analyses [22]. 


\section{Eligibility criteria Types of studies}

Randomized controlled trials (RCTs), randomized crossover studies, and cluster randomized trials were all eligible for this meta-analysis. No restrictions in terms of language and countries were applied.

\section{Types of participants}

Studies that included women (aged $\geq 18$ years) with sleep problems were eligible. No restrictions on the ethnicity and comorbidity of participants were applied.

\section{Types of interventions}

No restrictions regarding yoga type, form, structure, frequency, duration or length of intervention programs were applied. Studies on cointerventions that included yoga as a part of multicomponent interventions were excluded because it would be difficult to distinguish the effects of yoga from additional modalities. Studies in control interventions that compared yoga treatments with nontreatment, usual care, wait-lists, and education without active physical exercise programs were all eligible.

\section{Types of outcome measures}

The primary outcome of this study was sleep quality. To be included in this review, studies had to assess at least one of the sleep quality measures by using standardized instruments and provide outcomes both at the baseline and follow-up for primary outcomes. In particular, instruments in question include subjective measurements, such as the Pittsburgh Sleep Quality Index (PSQI) and Insomnia Severity Index (ISI), or objective measurements, such as polysomnography (PSG) and actigraphy. The PSQI score have been recommended as a reliable, valid and standardized instrument to measure and to identify quality of sleep. The widely employed Pittsburgh Sleep Quality Index (PSQI), provides a measure of global sleep quality, including sleep latency, sleep duration, habitual sleep efficiency, sleep disturbances, use of sleeping medication, and daytime dysfunction [14]. The seven components of the PSQI are standardized of areas routinely assessed sleep complaints with possible range of $0-21$ points. A global PSQI score of 5 or higher provided a sensitive and specific measure for poor sleep quality [14]. The ISI score is a reliable and valid instrument to quantify perceived insomnia severity. A global ISI score of 8 or higher is indicative of some degree of insomnia, while moderate insomnia has a score of 15-21 and severe insomnia with a score of 22-28 [23]. PSG or actigraphy reports the most complete and precise information on the construction and distribution of sleep periods, such as total sleep time (TST), sleep efficiency (SE), and wake time after sleep onset (WASO) [24]. Sleep quality is also sometimes measured from PSG and actigraphy. Among these objective indices are measures such as sleep onset latency, total sleep time, wake time after sleep onset, sleep efficiency, and number of awakenings [25].

Secondary outcomes: The secondary outcome included in this study was the safety of the intervention, which was assessed as number of patients with adverse events (AEs), including serious adverse events or nonserious events. Serious adverse events referred to those events that caused death, life-threatening situations, hospitalization, disability or permanent damage, congenital anomaly/birth defect, or the need for medical or surgical intervention to prevent any of the aforementioned outcomes [26]. All other adverse events were regarded as nonserious.

\section{Search methods}

The search strategy comprised four electronic databases from their inception through June 01, 2019: Medline/ PubMed, ClinicalKey, ScienceDirect, Embase, PsycINFO, and the Cochrane Library. The literature search was constructed around search terms for "yoga," "women," and "sleep" and was adapted for each database as necessary. The complete search strategy for PubMed was as follows: ("yoga" OR "asana" OR "pranayama" OR "dhyana") AND ("women" OR "female") AND ("sleep" OR "sleep quality" OR "sleep disturbance" OR "insomnia”). Additional reference lists of identified original articles or reviews, the table of the contents of the Journal of Yoga and Physical Therapy, and Journal of National Taiwan Sports University were searched manually.

Retrieved articles were scanned independently to verify their eligibility, and the entire text was assessed by two reviewers. A conflict of reviewers' opinions on inclusion or exclusion of any article was discussed with a third reviewer to reach a consensus.

\section{Data extraction and management}

Two reviewers independently extracted data on design (e.g., article setting, author/year, country of studies, and sampling strategy), participants (e.g., age, body max index, clinical characteristics, comorbid condition, and overall sample size), interventions (e.g., yoga type, frequency of sessions per week, duration of yoga intervention, and total length of intervention time), control interventions (e.g., type, frequency, length, and duration), and outcomes (e.g., outcome measures with sleep quality and safety-related events). A conflict of reviewers' opinions was discussed with a third reviewer until consensus was reached. 


\section{Risk of bias in individual studies}

Two reviewers independently assessed the risk of bias in each study. There were seven domains of assessment for the risk of bias include in the following: (1) random sequence generation, (2) allocation concealment, (3) blinding of participants and personnel, (4) blinding of outcome assessment, (5) incomplete outcome data, (6) selective reporting, and (7) other biases using the Cochrane Systematic Review Manual risk of bias assessment tool [22]. All domains were scored as low risk, high risk, or unclear risk of bias and assessed individually. A risk of bias table was completed for each included study. A conflict of reviewers' opinions was discussed with a third reviewer until consensus was reached.

\section{Data assessment of overall effect size}

A meta-analysis was conducted with Review Manager 5 software (Version 5.3, The Nordic Cochrane Centre, Copenhagen) and Comprehensive Meta-Analysis Software using a random effects model if at least two studies assessing this specific outcome were obtainable. For continuous outcomes, standardized mean differences (SMDs) with 95\% confidence intervals (CIs) were calculated as the difference in means between groups divided by the pooled standard deviation. For studies that did not report data with standard deviations, we calculated these values from standard errors, confidence intervals, or $t$-values. If adequate information was available, we would plan to perform subgroup analysis. The $p$ value of the summary effect $<0.05$ were regarded as indicating statistical significance.

A negative SMD was provided a definition to display the beneficial effects of yoga intervention compared with the control intervention for sleep quality outcomes. Cohen's categories were used to assess the significance of the overall effect size, with SMD $=0.2-0.5$ : small effect size; SMD = 0.5-0.8: medium effect size; and SMD > 0.8 : large effect size [27].

\section{Assessment of heterogeneity}

Statistical heterogeneity between studies was analyzed using the $\mathrm{I}^{2}$ statistics and the Cochrane chi-square. The variance between studies was measured using the tausquare $\left(\mathrm{Tau}^{2}\right)$. The level of heterogeneity was classified as $\mathrm{I}^{2}=0-24 \%$ : low heterogeneity; $\mathrm{I}^{2}=25-49 \%$ : moderate heterogeneity; $\mathrm{I}^{2}=50-74 \%$ : substantial heterogeneity; and $\mathrm{I}^{2}=75-100 \%$ : considerable heterogeneity. Given the low power of this test when only few studies or studies with a low sample size are included in a meta-analysis, a $P$ value of $\leq 0.1$ for the chi-square test was regarded as indicating significant heterogeneity [22].

\section{Moderator analyses}

Moderator and meta-regression analyses were further performed to identify possible reasons for interstudy heterogeneity. The subgroup analysis produced prespecified covariates, including outcome measurement tools, participant type, study quality, study region, participant age, intervention duration and study sample size.

\section{Risk of publication bias}

Risk of publication bias was evaluated for each metaanalysis that included at least 10 studies. Funnel plots generated using Review Manager 5 software was estimated from individual studies against each study's standard error. Publication bias was evaluated through visual analysis, in which roughly the symmetrical funnel plot signifies no evidence of high risk of publication bias [28]. Potential publication bias was evaluated using the Egger's Intercept Test, with $p$ values $<0.05$ signifying significant bias.

\section{Results \\ Literature search}

The results of the literature search and screening process are summarized in Fig. 1. The literature search totaled 1338 records; one additional record was retrieved from the Journal of National Taiwan Sports University in the Chinese language database [29]. In all, 1295 records were excluded because they did not meet all predefined inclusion criteria or were duplicated. Forty-four full-text articles were assessed for eligibility. Twenty-five were excluded because they were not randomized [29, 30], did not include relevant outcomes [31-37], did not include only female participants [38-46], included yoga as a part of a multimodal intervention (or combined with other intervention) [47-50], lacked adequate control [51], and did not include a form of yoga intervention [52, 53]. Nineteen full-text articles with 1832 participants were included in the qualitative synthesis and were included in the meta-analysis. All articles were published in English.

\section{Study characteristics}

A total of 19 studies were considered eligible for systematic reviews. Information regarding the characteristics of the sample, yoga or control group interventions, outcome measures, and results are listed in Tables 1 and 2 .

\section{Study and participant characteristics}

Of the 19 RCTs that were included in Table 1, six RCTs included healthy participants [60-63, 67, 69], including nurses [67], teachers [69], and women in the menopausal transition period or postmenopausal 


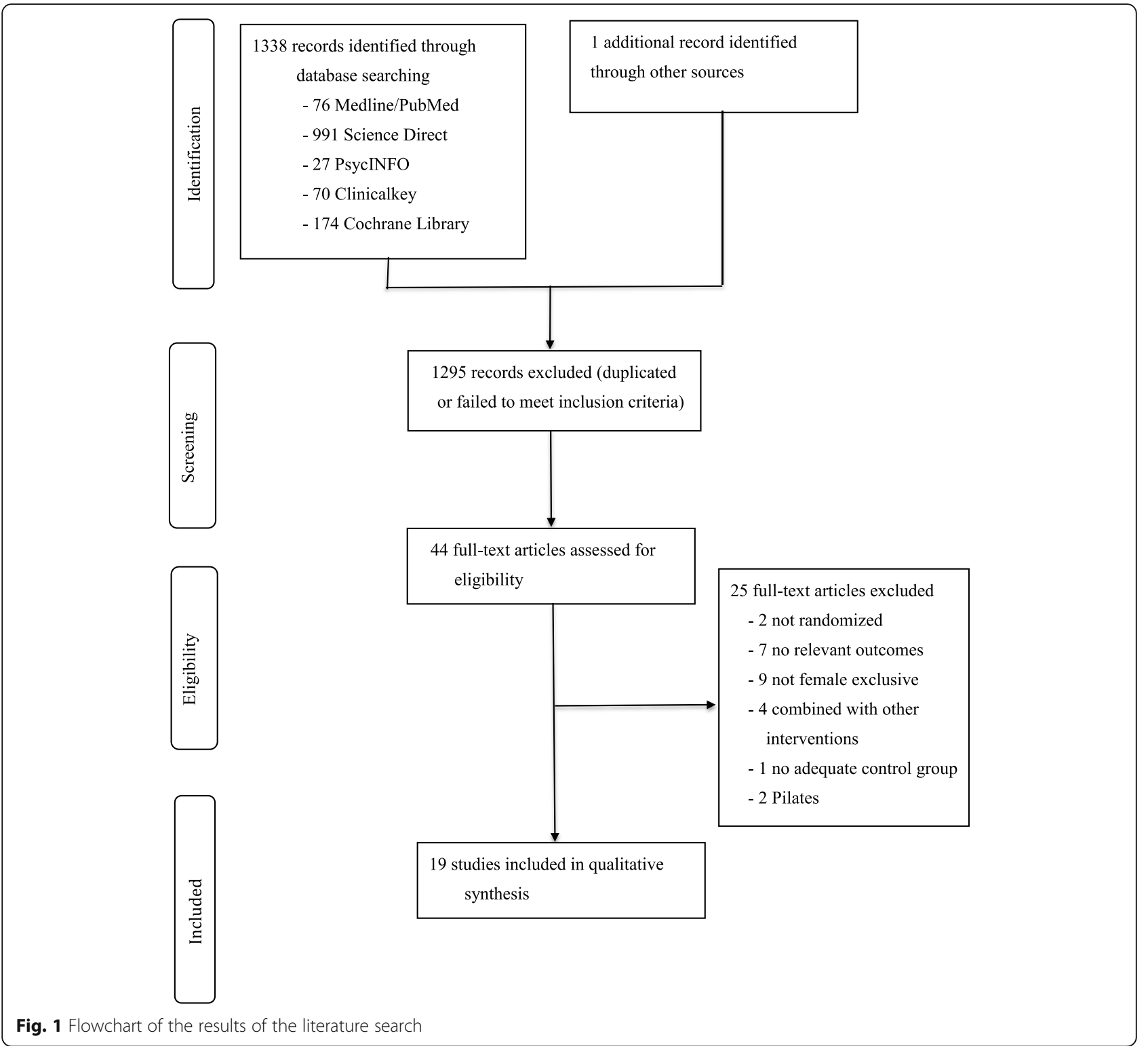

period [60-63]. The other 13 RCTs included breast cancer patients undergoing treatment [55, 57-59], breast cancer patients who had completed treatment [12, 54, 56, 71], type 2 diabetes mellitus patients [68], fibromyalgia patients [64], knee osteoarthritis patients [66], restless leg syndrome patients [65], and patients experiencing dysfunctional uterine bleeding [70].

Overall, the 19 RCTs included were conducted in the United States [12, 54-60, 62, 63, 65, 66, 71], Brazil [61, 64], India [69, 70], Iran [68], and China [67]. Study participants were recruited from hospitals $[54,55,57,58,67,68,70,71]$, outpatient clinics [59, 61] and schools [69]. The process of recruitment also included using purchased lists and health-plan enrollment files $[62,63]$ and multiple other mechanisms, including flyers, newspaper advertisements, web-based announcements, brochures, public health departments, tumor registry systems, and doctor referrals $[12,56$, $60,65,66]$. One study did not reveal the source from which participants were recruited [64]. Nineteen studies included in the systematic review displayed a baseline of PSQI higher than 5 or ISI higher than 8 , indicating poor sleep quality or insomnia. The only exceptions were two studies, with individual control groups in each study displaying a baseline of PSQI lower than 5 [69] or ISI lower than 8 [71]. The sample size ranged from 20 to 249 with a median of 96 . Participant's mean age ranged from 29.8 to 71.9 years, with a median of 50.1 years. All participants were women. 


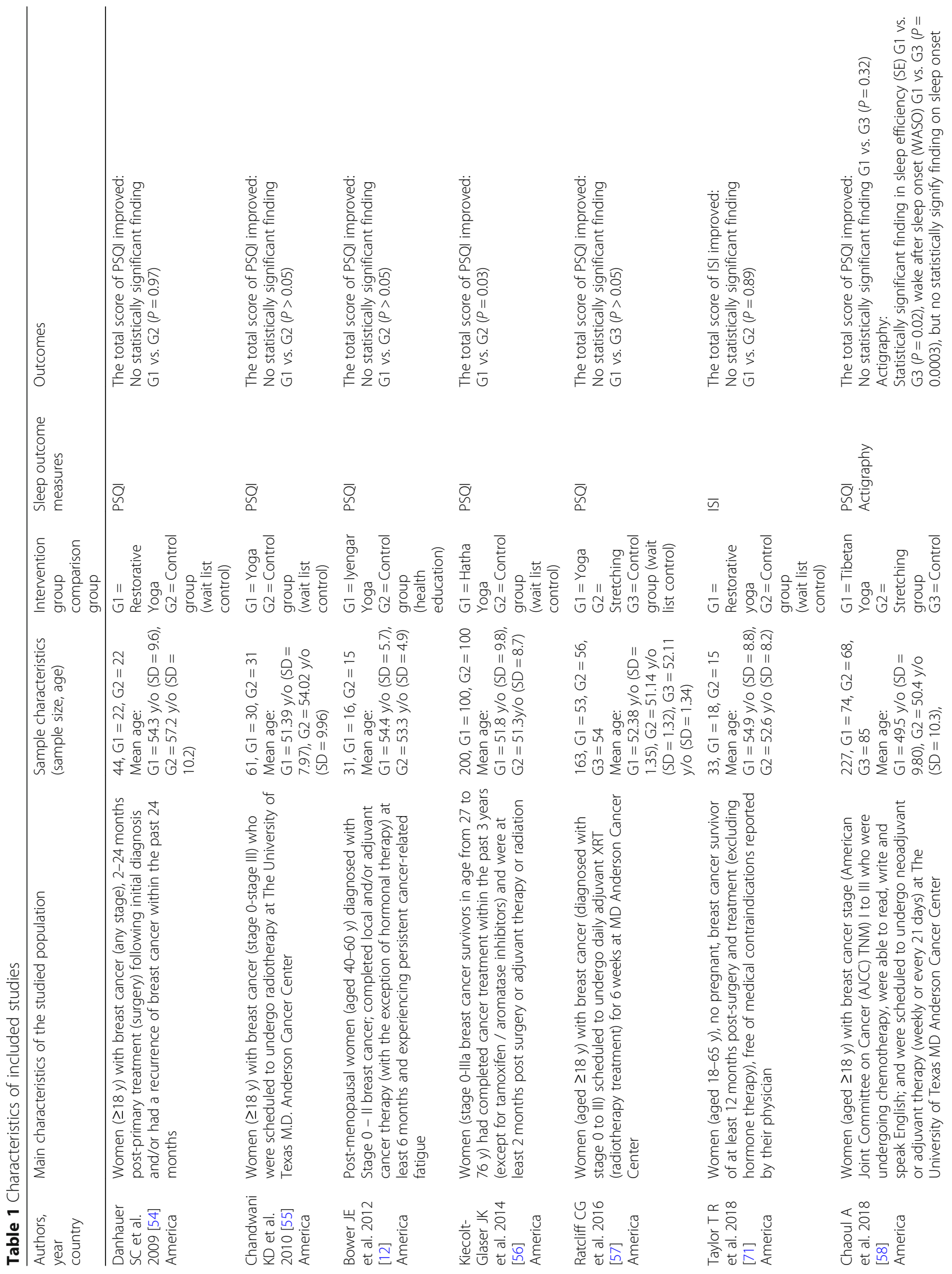




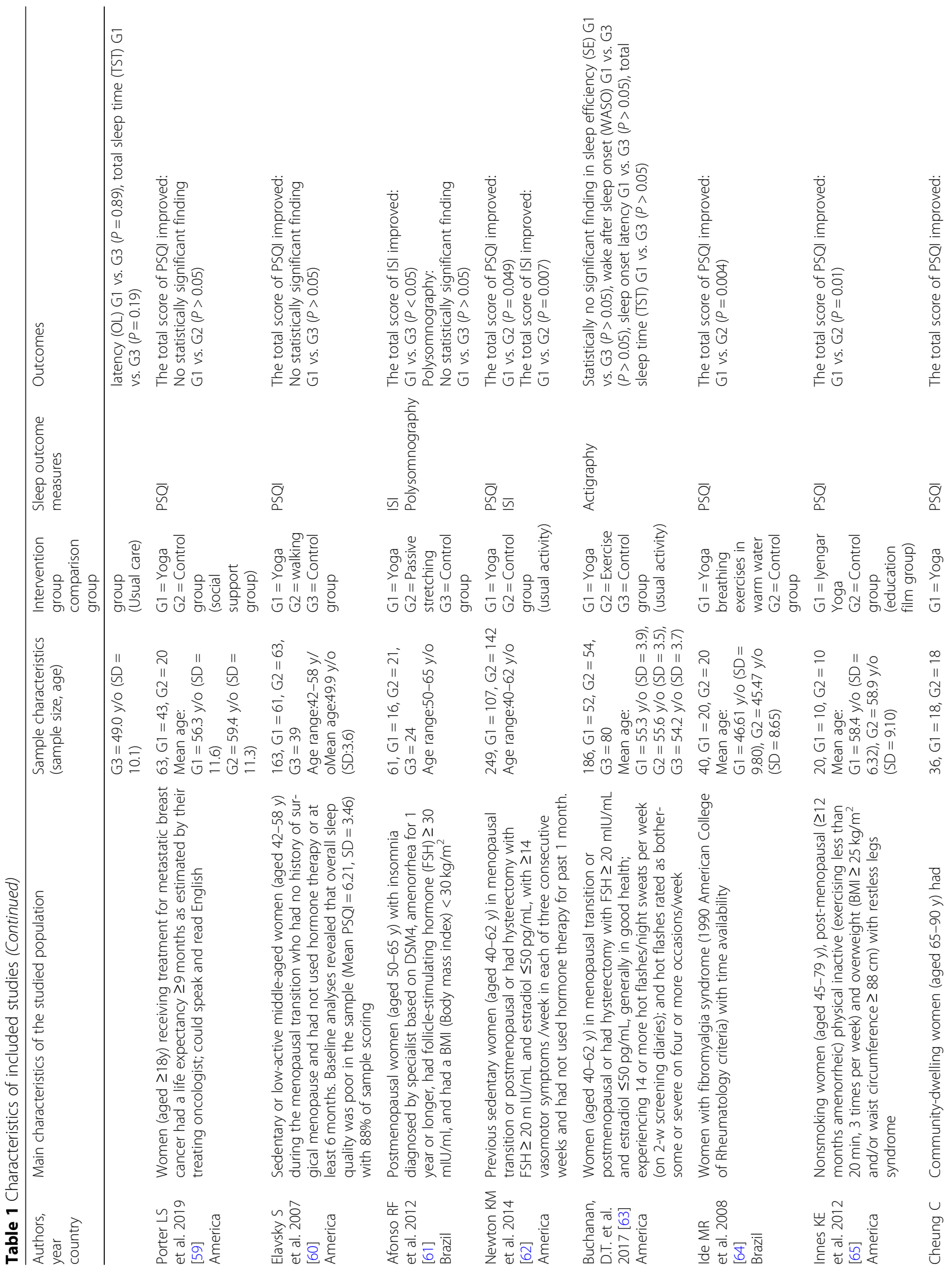


Wang et al. BMC Psychiatry

(2020) 20:195

Page 8 of 19

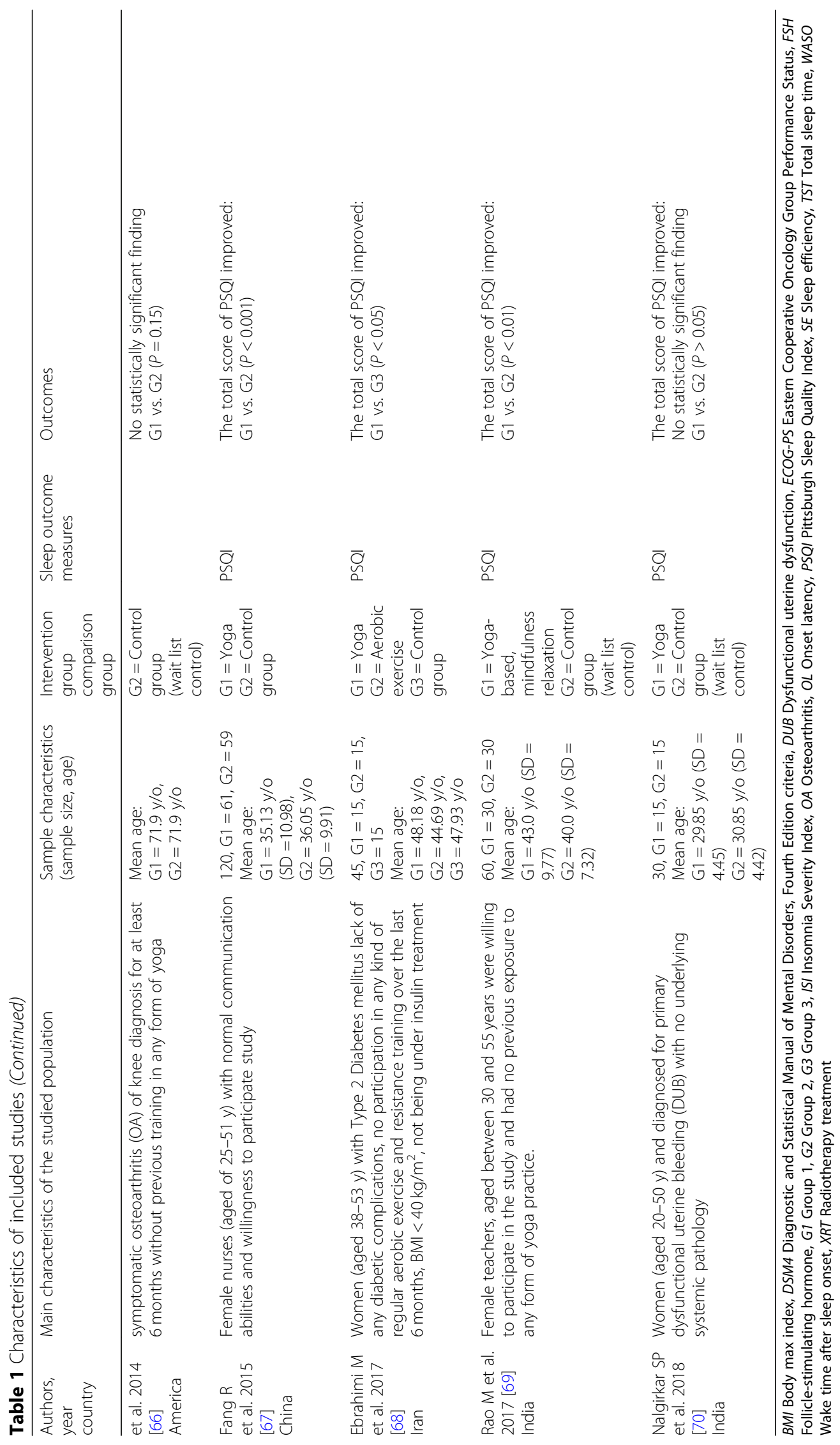


Table 2 Characteristics of yoga programs and outcome assessment of studies included in the systematic review

\begin{tabular}{|c|c|c|c|c|c|c|c|c|}
\hline $\begin{array}{l}\text { Authors, year } \\
\text { country }\end{array}$ & Specific type of yoga & $\begin{array}{l}\text { Yoga frequency } \\
\text { (sessions/week) }\end{array}$ & $\begin{array}{l}\text { Session } \\
\text { length } \\
\text { (mins/ } \\
\text { week) }\end{array}$ & $\begin{array}{l}\text { Study } \\
\text { duration } \\
\text { (weeks/ } \\
\text { study) }\end{array}$ & $\begin{array}{l}\text { Number of } \\
\text { sessions/ } \\
\text { study } \\
\text { Total lengths } \\
\text { (h)/study }\end{array}$ & $\begin{array}{l}\text { Safety } \\
\text { (adverse } \\
\text { events) }\end{array}$ & $\begin{array}{l}\text { Basal score of PSQI } \\
\text { (SD) and follow-up }\end{array}$ & $\begin{array}{l}\text { Basal score of ISI } \\
\text { (SD) and follow-up }\end{array}$ \\
\hline $\begin{array}{l}\text { Elavsky s et al. } \\
2007 \text { [60] } \\
\text { America }\end{array}$ & $\begin{array}{l}\text { lyengar Yoga } \\
\text { (Hatha Yoga) }\end{array}$ & 2 & 90 & 16 & $32(24 h)$ & $\begin{array}{l}\text { Not } \\
\text { reported }\end{array}$ & $\begin{array}{l}\mathrm{G} 1=6.90(3.94) \\
\mathrm{G} 1=6.48(4.22) \\
\mathrm{G} 3=5.46(2.96) \\
\mathrm{G} 3=5.44(3.63)\end{array}$ & - \\
\hline $\begin{array}{l}\text { Afonso RF et al. } \\
2012 \text { [61] } \\
\text { Brazil }\end{array}$ & Asanas Yoga & 2 & 120 & 16 & $32(32 h)$ & $\begin{array}{l}\text { Not } \\
\text { reported }\end{array}$ & - & $\begin{aligned} \mathrm{G} 1 & =14.1(5.87) \\
\mathrm{G} 1 & =9.7(4.64) \\
\mathrm{G} 3 & =15.2(4.8) \\
\mathrm{G} 3 & =13.7(4.64)\end{aligned}$ \\
\hline $\begin{array}{l}\text { Newton KM } \\
\text { et al. } 2014 \text { [62] } \\
\text { America }\end{array}$ & Yoga program & 2 & 90 & 12 & 24 (18h) & Reported & $\begin{array}{l}\mathrm{G} 1=7.7(3.34) \\
\mathrm{G} 1=5.6(3.30) \\
\mathrm{G} 2=8.4(3.30) \\
\mathrm{G} 2=5.8(2.91)\end{array}$ & $\begin{array}{l}\mathrm{G} 1=11.8(5.25) \\
\mathrm{G} 1=7.4(5.07) \\
\mathrm{G} 2=12.2(5.13) \\
\mathrm{G} 2=6.8(4.35)\end{array}$ \\
\hline $\begin{array}{l}\text { Buchanan, D.T. } \\
\text { et al. } 2017 \text { [63] } \\
\text { America }\end{array}$ & Viniyoga & 1 & 90 & 12 & $12(18 h)$ & $\begin{array}{l}\text { Not } \\
\text { reported }\end{array}$ & - & - \\
\hline $\begin{array}{l}\text { Danhauer SC } \\
\text { et al. } 2009 \text { [54] } \\
\text { America }\end{array}$ & Restorative Yoga & 1 & 75 & 10 & 10 (12.5 h) & $\begin{array}{l}\text { Not } \\
\text { reported }\end{array}$ & $\begin{array}{l}\mathrm{G} 1=8.3(4.7) \\
\mathrm{G} 1=6.1(4.3) \\
\mathrm{G} 2=8.6(5.3) \mathrm{G} 2= \\
7.0(4.2)\end{array}$ & - \\
\hline $\begin{array}{l}\text { Chandwani KD } \\
\text { et al. } 2010 \text { [55] } \\
\text { America }\end{array}$ & Yoga & 2 & 120 & 6 & $12(12 \mathrm{~h})$ & $\begin{array}{l}\text { Not } \\
\text { reported }\end{array}$ & $\begin{array}{l}\mathrm{G} 1=7.3(3.83) \mathrm{G} 1= \\
7.3(4.67) \\
\mathrm{G} 2=7.1(3.89) \mathrm{G} 2= \\
7.1(5.38)\end{array}$ & - \\
\hline $\begin{array}{l}\text { Bower JE et al. } \\
2012[12] \\
\text { America }\end{array}$ & lyengar Yoga & 2 & 90 & 12 & $24(36 h)$ & $\begin{array}{l}\text { Not } \\
\text { reported }\end{array}$ & $\begin{array}{l}\mathrm{G} 1=9.2(3.3) \\
\mathrm{G} 1=8.1(2.5) \\
\mathrm{G} 2=9.1(3.5) \\
\mathrm{G} 2=7.7(2.6)\end{array}$ & - \\
\hline $\begin{array}{l}\text { Kiecolt-Glaser KJ } \\
\text { et al. } 2014 \text { [56] } \\
\text { America }\end{array}$ & Hatha Yoga & 2 & 180 & 12 & $24(36 h)$ & Reported & $\begin{array}{l}\mathrm{G} 1=- \\
\mathrm{G} 1=7.0(2.15) \\
\mathrm{G} 2=- \\
\mathrm{G} 2=6.3(2.18)\end{array}$ & - \\
\hline $\begin{array}{l}\text { Cheung C et al. } \\
2014 \text { [66] } \\
\text { America }\end{array}$ & Hatha Yoga & 1 & 60 & 8 & 8 (8h) & $\begin{array}{l}\text { Not } \\
\text { reported }\end{array}$ & $\begin{array}{l}\mathrm{G} 1=6.5(4.2) \\
\mathrm{G} 1=5.0(2.2) \\
\mathrm{G} 2=5.4(2.8) \\
\mathrm{G} 2=6.1(2.2)\end{array}$ & - \\
\hline $\begin{array}{l}\text { Ratcliff CG et al. } \\
2016 \text { [57] } \\
\text { America }\end{array}$ & Yoga program & 3 & 180 & 6 & 18 (18h) & $\begin{array}{l}\text { Not } \\
\text { reported }\end{array}$ & $\begin{array}{l}\mathrm{G} 1=8.3(3.9) \\
\mathrm{G} 1=6.7(3.1) \\
\mathrm{G} 3=8.2(3.7) \\
\mathrm{G} 3=7.3(3.7)\end{array}$ & - \\
\hline $\begin{array}{l}\text { Taylor TR et al. } \\
2018 \text { [71] } \\
\text { America }\end{array}$ & Restorative Yoga & 1 & 75 & 8 & $8(10 h)$ & $\begin{array}{l}\text { Not } \\
\text { reported }\end{array}$ & - & $\begin{aligned} \mathrm{G} 1 & =10.18(8.74) \\
\mathrm{G} 1 & =7.89(7.17) \\
\mathrm{G} 2 & =7.56(6.82) \\
\mathrm{G} 2 & =6.20(7.11)\end{aligned}$ \\
\hline $\begin{array}{l}\text { Chaoul A et al. } \\
2018 \text { [58] } \\
\text { America }\end{array}$ & Tibetan Yoga & 4 & $\begin{array}{l}300- \\
360\end{array}$ & 1 & $4(5-6 h)$ & $\begin{array}{l}\text { Not } \\
\text { reported }\end{array}$ & $\begin{array}{l}\mathrm{G} 1=7.8(3.7) \\
\mathrm{G} 1=7.3(3.6) \\
\mathrm{G} 3=8.1(4.2) \\
\mathrm{G} 3=8.1(4.4)\end{array}$ & - \\
\hline $\begin{array}{l}\text { Porter LS et al. } \\
2019 \text { [59] } \\
\text { America }\end{array}$ & Mindful Yoga & 1 & 120 & 8 & $8(16 h)$ & $\begin{array}{l}\text { Not } \\
\text { reported }\end{array}$ & $\begin{array}{l}\mathrm{G} 1=8.6(3.34) \mathrm{G} 1= \\
8.6(3.01) \\
\mathrm{G} 2=7.6(2.73) \mathrm{G} 2= \\
7.6(3.42)\end{array}$ & - \\
\hline $\begin{array}{l}\text { Ide MR et al. } \\
2008 \text { [64] } \\
\text { Brazil }\end{array}$ & $\begin{array}{l}\text { Yoga breathing } \\
\text { exercises in warm } \\
\text { water }\end{array}$ & 4 & 240 & 4 & $16(16 h)$ & $\begin{array}{l}\text { Not } \\
\text { reported }\end{array}$ & $\begin{array}{l}\mathrm{G} 1=13.17(4.00) \\
\mathrm{G} 1=9.95(1.15) \\
\mathrm{G} 2=11.82(5.05) \\
\mathrm{G} 2=13.88(1.28)\end{array}$ & - \\
\hline Innes K E et al. & lyengar yoga & 2 & 180 & 8 & $16(24 h)$ & Not & $\mathrm{G} 1=8.71(3.63)$ & - \\
\hline
\end{tabular}


Table 2 Characteristics of yoga programs and outcome assessment of studies included in the systematic review (Continued)

\begin{tabular}{|c|c|c|c|c|c|c|c|c|}
\hline $\begin{array}{l}\text { Authors, year } \\
\text { country }\end{array}$ & Specific type of yoga & $\begin{array}{l}\text { Yoga frequency } \\
\text { (sessions/week) }\end{array}$ & $\begin{array}{l}\text { Session } \\
\text { length } \\
\text { (mins/ } \\
\text { week) }\end{array}$ & $\begin{array}{l}\text { Study } \\
\text { duration } \\
\text { (weeks/ } \\
\text { study) }\end{array}$ & $\begin{array}{l}\text { Number of } \\
\text { sessions/ } \\
\text { study } \\
\text { Total lengths } \\
\text { (h)/study }\end{array}$ & $\begin{array}{l}\text { Safety } \\
\text { (adverse } \\
\text { events) }\end{array}$ & $\begin{array}{l}\text { Basal score of PSQI } \\
\text { (SD) and follow-up }\end{array}$ & $\begin{array}{l}\text { Basal score of ISI } \\
\text { (SD) and follow-up }\end{array}$ \\
\hline $\begin{array}{l}2012 \text { [65] } \\
\text { America }\end{array}$ & & & & & & reported & $\begin{array}{l}\mathrm{G} 1=3.57(1.49) \\
\mathrm{G} 2=9.25(3.32) \\
\mathrm{G} 2=8.00(2.94)\end{array}$ & \\
\hline $\begin{array}{l}\text { Fang R et al. } \\
2015 \text { [67] } \\
\text { China }\end{array}$ & Yoga & $>2$ & $\begin{array}{l}>100- \\
120\end{array}$ & 24 & $\begin{array}{l}>48(40-48 \\
\text { h) }\end{array}$ & $\begin{array}{l}\text { Not } \\
\text { reported }\end{array}$ & $\begin{array}{l}\mathrm{G} 1=9.98(1.89) \\
\mathrm{G} 1=7.61(1.25) \\
\mathrm{G} 2=10.24(2.35) \\
\mathrm{G} 2=10.31(2.42)\end{array}$ & - \\
\hline $\begin{array}{l}\text { Ebrahimi M et al. } \\
2017 \text { [68] } \\
\text { Iran }\end{array}$ & Yoga program & 3 & 270 & 12 & 36 (54 h) & $\begin{array}{l}\text { Not } \\
\text { reported }\end{array}$ & $\begin{array}{l}\mathrm{G} 1=14.40(5.92) \\
\mathrm{G} 1=3.73(3.49) \\
\mathrm{G} 3=13.91(5.52) \\
\mathrm{G} 3=13.27(5.58)\end{array}$ & - \\
\hline $\begin{array}{l}\text { Rao, M et al. } \\
2017 \text { [69] } \\
\text { India }\end{array}$ & $\begin{array}{l}\text { Yoga-based, } \\
\text { mindfulness } \\
\text { relaxation }\end{array}$ & 5 & 150 & 4 & $20(10 h)$ & $\begin{array}{l}\text { Not } \\
\text { reported }\end{array}$ & $\begin{array}{l}\mathrm{G} 1=5.63(3.31) \\
\mathrm{G} 1=3.10(1.26) \\
\mathrm{G} 2=4.86(2.52) \\
\mathrm{G} 2=5.9(1.93)\end{array}$ & - \\
\hline $\begin{array}{l}\text { Nalgirkar SP } \\
\text { et al. } 2018 \text { [70] } \\
\text { India }\end{array}$ & Yoga program & 3 & 180 & 12 & $36(h)$ & $\begin{array}{l}\text { Not } \\
\text { reported }\end{array}$ & $\begin{array}{l}\mathrm{G} 1=15.16(8.29) \\
\mathrm{G} 1=12.75(4.73) \\
\mathrm{G} 2=9.91(4.69) \\
\mathrm{G} 2=10.08(3.75)\end{array}$ & - \\
\hline
\end{tabular}

\section{Intervention characteristics}

Of the 19 included studies in Table 1, three reported using Iyengar Yoga [12, 60, 65]; two reported using Hatha Yoga [56, 66]; two reported using Tibetan Yoga $[58,61]$; two reported using Restorative Yoga [54, 71]; one reported using Vini Yoga [63]; one reported using Yoga Relaxation with MindSound Resonance Technique [69]; one reported using yoga breathing exercise in warm water [64]; and only seven RCTs revealed yoga programs with postures, breathing, relaxation or mediation, without defining a specific style of yoga $[55,57,59,62,67$, $68,70]$. All RCTs included yoga postures in their yoga intervention; 16 RCTs included yoga breathing; 15 RCTs included yoga relaxation; 12 RCTs included meditation; and 7 RCTs included all contents with postures, breathing, relaxation, and meditation for the yoga intervention group $[55,57,62,67,68,70,71]$. The duration of yoga interventions ranged from 1 week to 24 weeks, with a median of 10 weeks; the frequency of yoga interventions ranged from one to five weekly sessions of 45 to 120 min. Sixteen studies compared the yoga group with waitlist control groups with no specific treatment; three studies compared the yoga group with the control group, including two studies for education groups [12, 65] and one study for social support groups [59].

\section{Outcome measures}

All studies evaluated outcomes directly at the end of interventions. All studies assessed the subjective or objective measurements of sleep quality: 16 RCTs used the PSQI; three RCTs used the ISI [61, 62, 71]; one RCT used PSG [61]; and two RCTs used actigraphy [58, 63]. Safety-related events were reported in only two RCTs $[56,62]$.

\section{Risk of bias \\ Risk of bias in individual assessments}

Graphical representation of the risk-of-bias assessment is represented in Fig. 2. All studies had a high or unclear risk of bias in at least one domain. All studies claimed to be randomized; however, three studies did not reveal their content and method of random sequence [54, 61, 68]. Twelve studies did not report methods applied to perform adequate allocation [54, 55, 57-61, 63, 67-70]. Most studies offered no data material on blinding. Three studies clearly reported that participants and personnel were blinded $[12,59,66]$. Four studies clearly reported that researchers and outcome assessments were blinded $[12,56,59,66]$. Six studies had insufficient data on attrition rates $[60-62,64,65,68]$. Twelve studies had a low risk of selection reporting; only two studies had a high risk of selective reporting due to several reported outcome parameters not being revealed in study protocol or duplicate publications reporting different results of the same trial $[61,62]$. Six studies had a high risk of other potential sources of bias due to poor participant compliance, intervention length, sample size or baseline differences $[60,64-66,70,71]$.

\section{Publication bias}

The meta-analysis of the effect of yoga on the sleep quality of women that involved yoga groups compared 


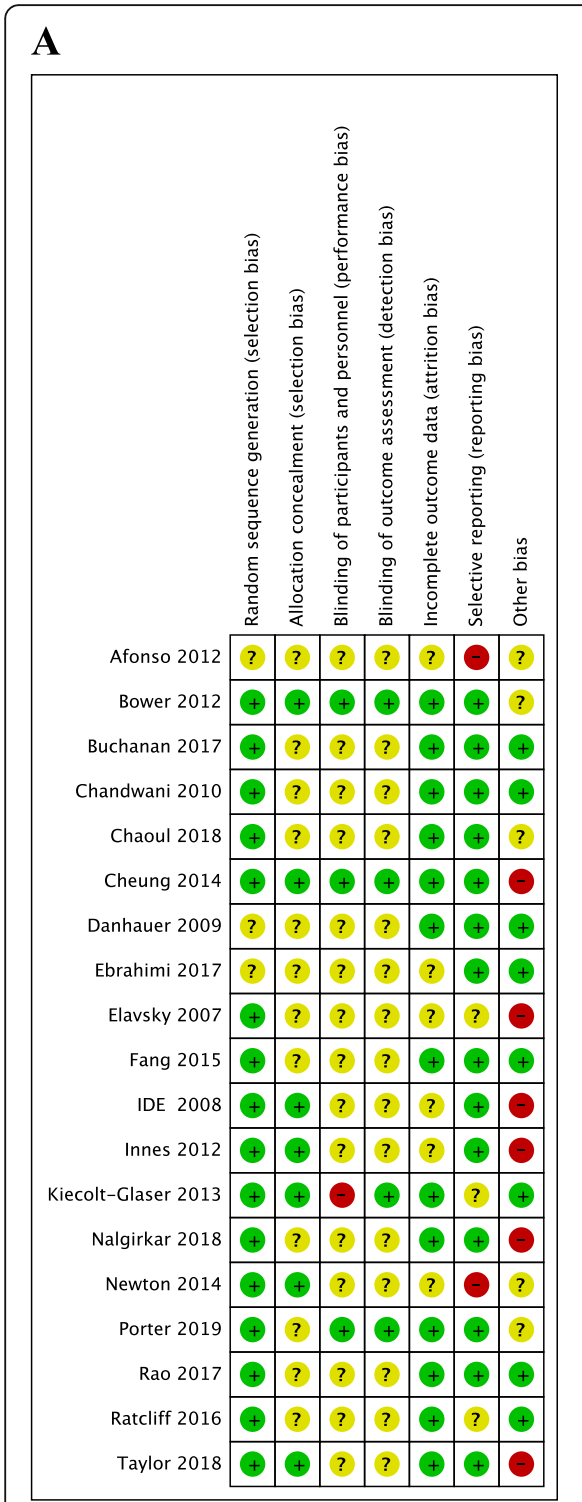

B

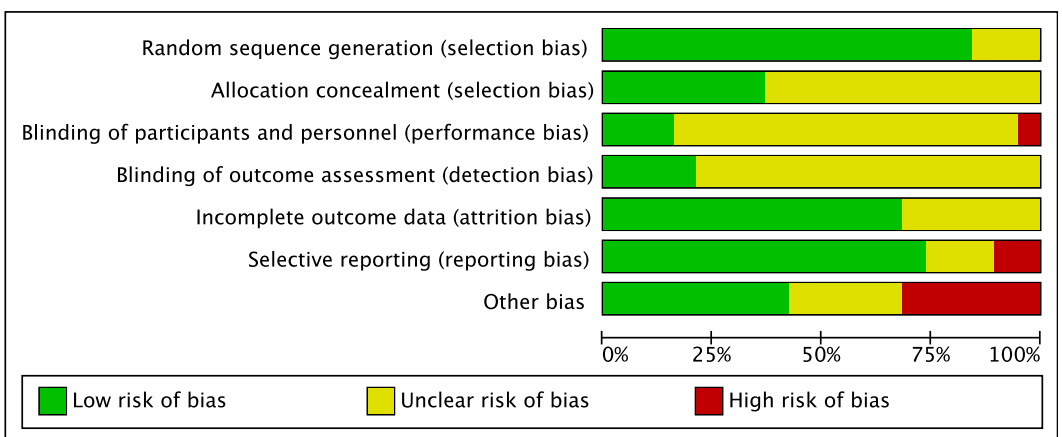

Fig. 2 Risk of bias in individual studies. +, low risk of bias;?, unclear risk of bias; -, high risk of bias (a). Risk of bias for each criterion presented as percentages across all included studies (b)

with control groups included 16 studies. The asymmetrical shape of the funnel plot indicated that subjective publication bias was detected (Fig. 3). Objective publication bias was analyzed using Egger's Regression Test. Egger's Test consists of the regression between the accuracy of the studies and standardized effects, which are weighted by the inverse of variance. Borderline findings $(P=0.05)$ show objective evidence on publication bias between precision and standardized effects of studies in the present study, specifically suggesting need for future studies to expound on the issue.

\section{Analysis of overall effects Primary outcomes}

The random effects model was applied to analyze the 19 RCTs outcomes by different sleep outcome measurement tools. The meta-analysis of combined data conducted with Comprehensive Meta-Analysis, showed a significant improvement in sleep problems $(\mathrm{SMD}=$ $0.327,95 \% \mathrm{CI}=-0.506$ to $-0.148, P<0.001)$. However, significant heterogeneity existed among all the studies $\left(\mathrm{Q}=43.152, \mathrm{I}^{2}=58.287 \%, P=0.001\right)$. Therefore, moderator and meta-regression analyses were conducted to further explore the determinants of the heterogeneity. 


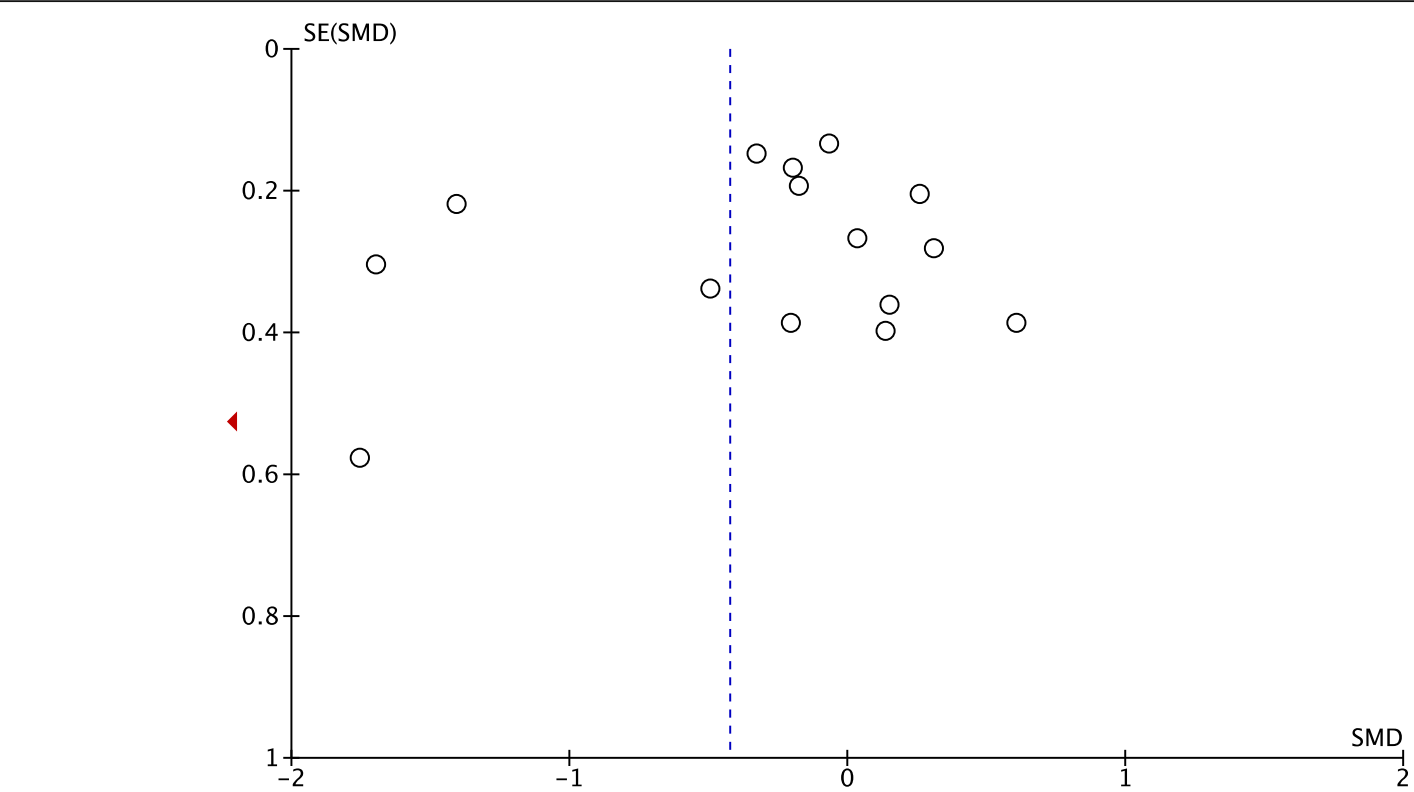

Fig. 3 Funnel plot of estimate of publication bias in meta-analysis of the effects of yoga on women's sleep quality compared to control groups (PSQI). SE: standard error; SMD: standardized mean difference

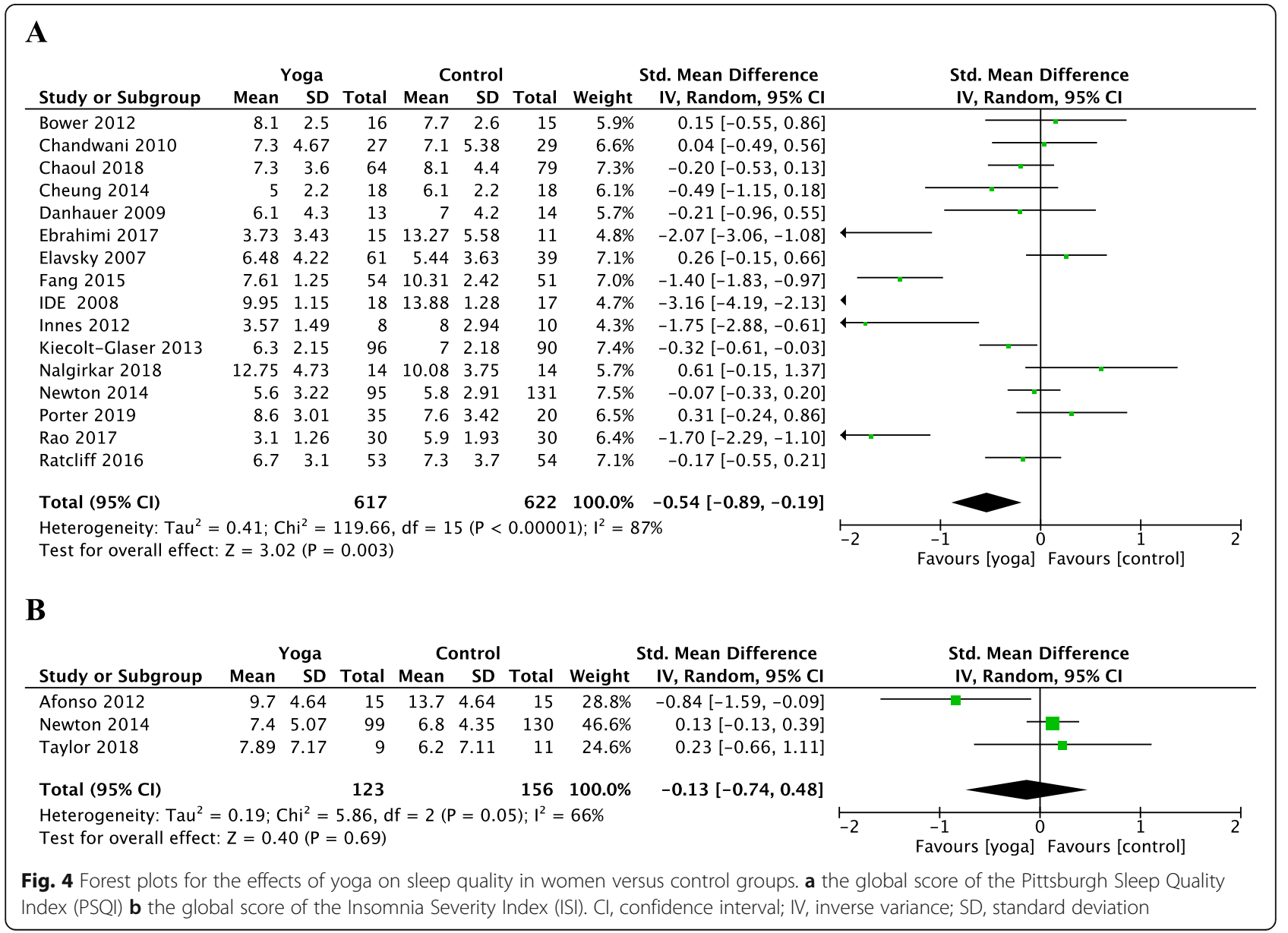


The meta-analysis revealed the effects of yoga compared with the control group on the sleep quality and insomnia of women using the PSQI or ISI, as displayed in Fig. 4. Sixteen RCTs revealed evidence for effects of yoga compared with the control group in improving sleep quality in women using the PSQI (SMD $=-0.54$; 95\% $\mathrm{CI}=-0.89$ to $-0.19 ; P=0.003)$. However, three RCTs revealed no effects of yoga compared with the control group in reducing the severity of insomnia in women using ISI $(\mathrm{SMD}=-0.13 ; 95 \% \mathrm{CI}=-0.74$ to $0.48 ; P=$ 0.69). Two RCTs revealed no effects of yoga compared with control group in improving sleep efficiency $(\mathrm{SMD}=$ $0.85 ; 95 \% \mathrm{CI}=-0.56$ to $2.26 ; P=0.26$ ) or total sleep time $(\mathrm{SMD}=-0.06 ; 95 \% \mathrm{CI}=-0.26$ to $0.13 ; P=-0.59)$ in women using actigraphy.

\section{Secondary outcomes (safety)}

Only two studies reported safety-related events. Two events revealed in one study could potentially be attributed to yoga intervention: two women reported the recurrence of chronic back and/or shoulder problems [56]. In another study, adverse events reported did not differ between the yoga intervention group and the control group $(P=0.41)$. These adverse events included muscle aches and strains (6.7\%, yoga group; 10.3\%, control group), low back pain (4.2\%, yoga group; $3.1 \%$, control group), or changes in strength or sensation in arms and legs (5.5\% yoga group; $8.9 \%$ control group). Dropouts were not regarded as being adverse events because they did not explicitly show a possible reason or explanation for dropout in the original study. No serious adverse effects were reported in the included studies.

\section{Subgroup analyses}

Participants were divided into two separate subgroups. Meta-analyses revealed the effects of yoga compared with the control group for women with breast cancer in Fig. 5 . Seven RCTs revealed no evidence for the effect of yoga compared with the control group in improving sleep quality for women with breast cancer using the PSQI (SMD = $-0.15 ; 95 \% \mathrm{CI}=-0.31$ to $0.01 ; P=0.5$ ). Four RCTs revealed no evidence for effects of yoga compared with the control group in improving sleep quality for women undergoing treatment for breast cancer $(S M D=-0.08$; 95\% CI $=-0.29$ to $0.13 ; P=0.45$ ). Three RCTs revealed no evidence for positive effects of yoga in terms of improving sleep quality for women with breast cancer who had completed treatment compared with the control group $(\mathrm{SMD}=-0.25 ; 95 \% \mathrm{CI}=-0.50$ to $0.00 ; P=0.05)$.

The meta-analysis showed evidence of the positive effects of yoga on sleep quality compared with control groups for peri/postmenopausal women as displayed in Fig. 6. Four RCTs revealed no evidence for effects of yoga compared with control groups in improving sleep quality in peri/postmenopausal women using the PSQI $(\mathrm{SMD}=-0.31 ; 95 \% \mathrm{CI}=-0.95$ to $0.33 ; P=0.34)$. Two RCTs revealed no evidence for effects of yoga compared with the control group in reducing severity of insomnia in peri/postmenopausal using ISI $(S M D=-0.29 ; 95 \%$ $\mathrm{CI}=-1.23$ to $0.65 ; P=0.55$ ).

\section{Moderator analyses, meta-regression}

Moderator analyses and meta-regression are presented in Table 3. Significant factors in observed heterogeneity were identified in yoga on sleep quality and insomnia in women with sleep problems. Studies that used PSQI as outcome measurement tool showed a greater reduction in sleep problems than other studies that used other instruments as outcome measurement tools (Hedges' $\mathrm{g}=-$ 0.369 vs. $0.031, P=0.002$ ). Participants without breast cancer showed more improvement in sleep problems than participants with breast cancer (Hedges' $\mathrm{g}=-0.522$ vs. $-0.148, P=0.001)$. Studies without peri/postmenopausal women showed more improvement in sleep problems than studies with peri/postmenopausal women (Hedges' $\mathrm{g}=-0.419$ vs. $-0.084, P=0.003$ ). Regression analyses revealed a positive correlation with total length of class hours $(p=0.003)$, indicating that more total class hours, increased the chance to have significant results. Regression analyses revealed a negative correlation with mean age $(p=0.003)$ and sample size $(p=0.032)$ of study, indicating that the younger, and smaller sample sizes were more likely to have significant results.

\section{Sensitivity analyses}

In the included studies with low risk of selection bias, reporting bias, and other bias, the effect of yoga group compared to control group on women sleep PSQI did not change substantially, including random sequence generation bias $(\mathrm{SMD}=-0.45 ; 95 \% \mathrm{CI}=-0.84$ to $-0.11 ; P=$ 0.01; heterogeneity: $\left.\mathrm{I}^{2}=88 \% ; X^{2}=107.43, P<0.00001\right)$, allocation concealment bias $(\mathrm{SMD}=-0.77 ; 95 \% \mathrm{CI}=-1.37$ to $-0.16 ; P=0.01$; heterogeneity: $\mathrm{I}^{2}=88 \% ; \chi^{2}=40.95, P<$ 0.00001 ), selective reporting bias (standard mean difference $=-0.59 ; 95 \% \mathrm{CI}=-1.10$ to $-0.08 ; P=0.02$; heterogeneity: $\left.\mathrm{I}^{2}=88 \% ; X^{2}=93.11, P<0.00001\right)$ and other bias (standard mean difference $=-0.53 ; 95 \% \mathrm{CI}=-1.03$ to 0.04; $P=0.03$; heterogeneity: $I^{2}=86 \% ; X^{2}=44.03, \quad P<$ $0.00001)$. The effect compared with the control group remained significant in terms of sensitivity analyses of performance bias, detection bias, or attrition bias after eliminating high risk bias or uncertain risk bias of the studies.

\section{Discussion}

\section{Summary of evidence}

In this systematic review of 19 studies for yoga's effect on improving women's sleep quality and severity of 


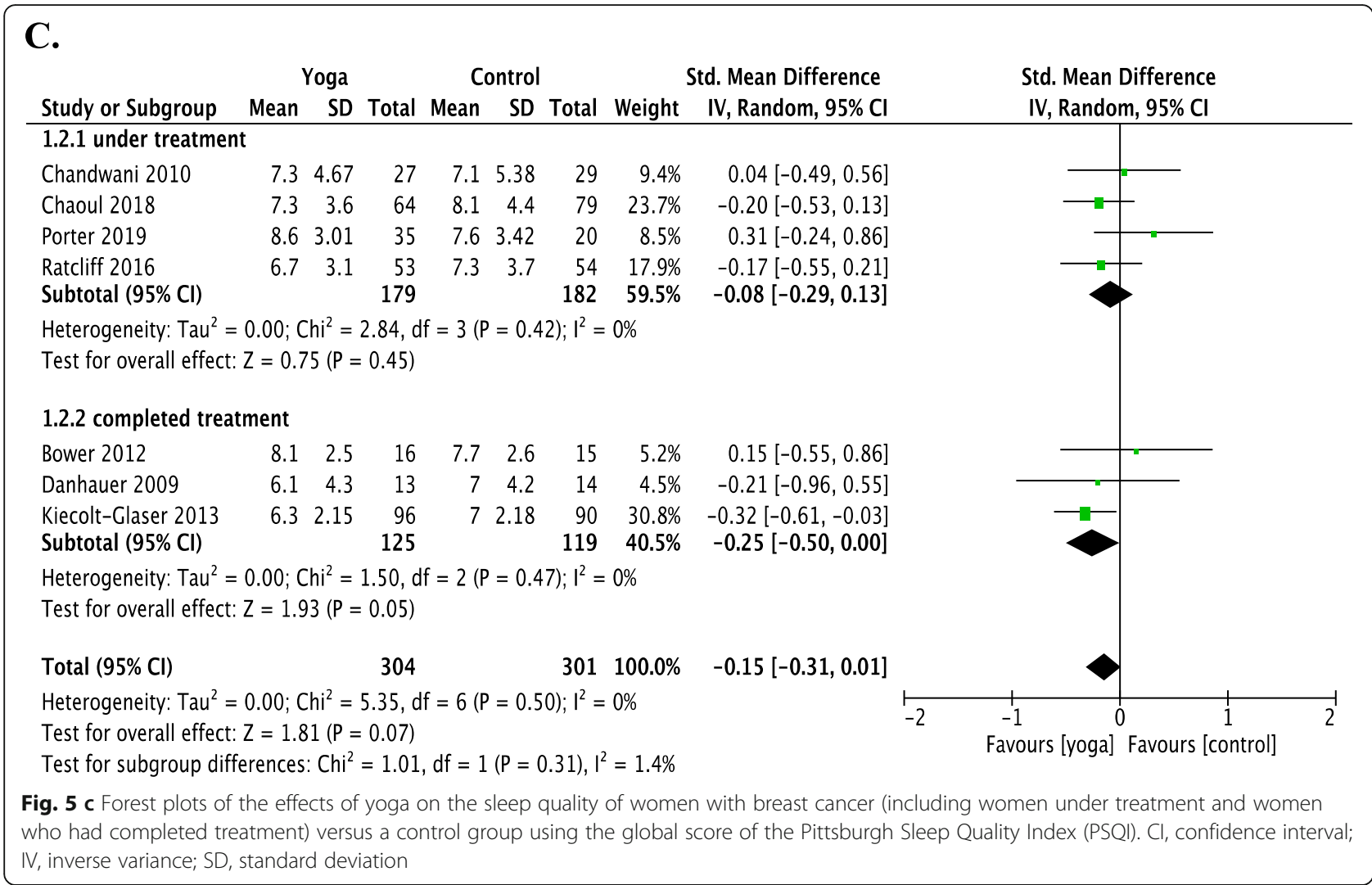

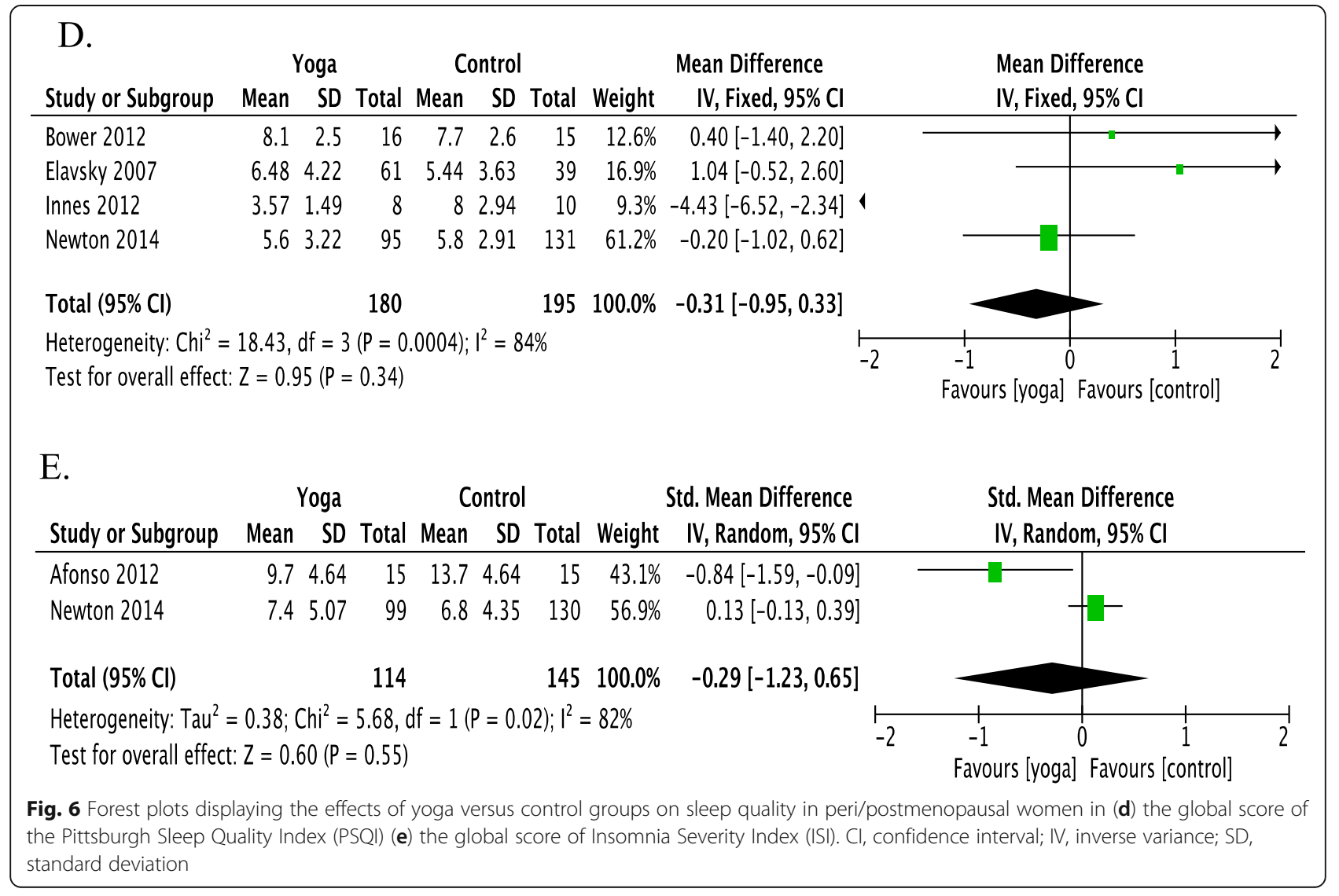


Table 3 Mean effect sizes and moderator analyses of yoga in women with sleep problems

\begin{tabular}{|c|c|c|c|c|}
\hline Parameter & Results & $\begin{array}{l}\text { Effect Size } \\
\text { (Hedges'g) }\end{array}$ & $95 \% \mathrm{Cl}$ & $P$ \\
\hline \multicolumn{5}{|l|}{ Categorical Moderators } \\
\hline \multicolumn{5}{|l|}{ Outcome measurement tool } \\
\hline PSQI & 16 & -0.369 & $-0.559,-0.178$ & \multirow[t]{2}{*}{$0.002^{*}$} \\
\hline Others & 3 & 0.031 & $-0.265,0.328$ & \\
\hline \multicolumn{5}{|l|}{ Participant } \\
\hline Breast cancer group & 8 & -0.148 & $-0.304,0.009$ & \multirow[t]{2}{*}{$0.001^{*}$} \\
\hline Non-breast cancer group & 11 & -0.522 & $-0.821,-0.224$ & \\
\hline \multicolumn{5}{|l|}{ Participant } \\
\hline Peri/postmenopausal & 6 & -0.084 & $-0.269,0.102$ & \multirow[t]{2}{*}{$0.003^{*}$} \\
\hline Others & 13 & -0.419 & $-0.647,-0.191$ & \\
\hline \multicolumn{5}{|l|}{ Study region } \\
\hline American & 13 & -0.123 & $-0.240,-0.006$ & \multirow[t]{2}{*}{$<0.001^{*}$} \\
\hline Others & 6 & -0.844 & $-1.114,-0.573$ & \\
\hline \multicolumn{5}{|c|}{ Random sequence generation } \\
\hline High/ unclear risk & 3 & -0.578 & $-1.272,0.116$ & \multirow[t]{2}{*}{$0.001^{*}$} \\
\hline Low risk & 16 & -0.292 & $-0.473,-0.111$ & \\
\hline \multicolumn{5}{|l|}{ Continuous Moderators } \\
\hline Sample size & 19 & & $0.000,0.003$ & $0.032^{*}$ \\
\hline Total length of class time & 19 & & $-0.021,-0.004$ & $0.003^{*}$ \\
\hline Study duration & 19 & & $-0.03,0.087$ & 0.20 \\
\hline Mean age & 17 & & $0.008,0.035$ & $0.003^{*}$ \\
\hline
\end{tabular}

${ }^{*} P$ value $<0.05$ indicated a significant difference

insomnia, 19 RCTs revealed evidence for yoga improving sleep problems in women $(\mathrm{SMD}=-0.327,95 \% \mathrm{CI}=-$ 0.506 to $-0.148, P<0.001$ ). As shown in Fig. 4,16 RCTs meta-analysis suggests yoga can bring 1.2 points improvement in PSQI score $(\mathrm{SMD}=-0.54 ; 95 \% \mathrm{CI}=-$ 0.89 to $-0.19 ; P=0.003)$. However, seven RCTs revealed no evidence for yoga improving sleep quality in women with breast cancer (Fig. 5, SMD $=-0.15 ; 95 \% \mathrm{CI}=-0.31$ to $0.01 ; P=0.5)$. Four RCTs revealed no evidence for improving PSQI in peri/postmenopausal women (Fig. 6, $\mathrm{SMD}=-0.31 ; 95 \% \mathrm{CI}=-0.95$ to $0.33 ; P=0.34$ ). Two RCTs revealed no evidence for improving ISI in peri/ postmenopausal women (Fig. 6, SMD $=-0.29 ; 95 \% \mathrm{CI}=$ -1.23 to $0.65 ; P=0.55$ ).

However, heterogeneity of effects were high across all studies. In Table 3, our moderator analyses yielded statistically significant differences, the effect of yoga for improving sleep problems in non-breast cancer subgroup, non peri/postmenopausal subgroup are superior to breast cancer subgroup, peri/postmenopausal subgroup.

Overall, the application of yoga was not associated with worsening of sleep problems or increased adverse effects. Only two studies explicitly assessed safety-related nonserious adverse events. Yoga is most likely a comparatively safe intervention in this population. However, future RCTs should take more measures to ensure stricter reporting of adverse events and reasons for dropouts.

\section{Comparison with prior reviews}

There was no systematic review available that explicitly focused on yoga for improving sleep quality and insomnia in a specific gender. Ours is the first systematic review and meta-analysis with 19 RCTs that to focus on the effects of yoga on women with sleep problems. A previous review published until February 2019 included subgroup analysis of yoga on mind-body therapies on insomnia [72]. This recent review illustrated that yoga had beneficial effects on subjective sleep quality in participants in all gender groups. Our meta-analysis with 16 RCTs uncovered evidence for the effects of yoga on the sleep quality in women. Only six RCTs were found to have overlapped with this previous review [58, 61, 62, 65-67]. Our meta-analysis also examined the potential effect on specific subgroups, such as breast cancer and peri/postmenopausal subgroups, with these subgroups serving as potential factors in sleep quality effects (although the result did not show any clear difference). Significant subgroup differences were identified for the 
following participants types: (peri/postmenopausal vs. non peri/postmenopausal, breast cancer vs. non-breast cancer). Results from the peri/postmenopausal subgroup of women in our systematic review also agreed with previous published reports that suggested that yoga had no significant effect on the severity of insomnia in middleaged women [73]. There were baseline differences between participants based on intervention assignment in PSQI scores [62, 65]. This may have contributed to results displaying no significant effect in sleep quality in the peri/postmenopausal subgroup of women. Yoga seems to be effective for reducing total menopausal symptoms including psychological, somatic, vasomotor and in previous systematic review and meta-analysis [74], but there is no direct answer in the study focusing on reducing sleep problems. Future research should ensure more rigorous methodology and adequate sample size concerning the effects of yoga on quality of sleep improvement among the subgroup of peri/postmenopausal women.

Compared to yoga intervention, previous systematic reviews also indicate that programmed exercise improved sleep quality in middle-aged women [73]. However, these reviews are also limited to high heterogeneity of clinical evidence and failed to provide any specific suggestions for exercise dosages or formats. Additionally, other reviews included an overly wide range of nonpharmacological interventions ranging from walking [75], tai chi [76], qigong exercise [72] showing evidence of beneficial effect in improving self-rated sleep quality. However, despite this, heterogeneity remained high due to difference of interventions and target populations. Our meta-analysis conducted to further explore the determinants of the heterogeneity with subgroup analysis for categorical moderators and continuous moderators to find significant factors for observed heterogeneity.

\section{External and internal validity}

Major threats to external validity included the specificity of variables of sampled participants and multiple yoga types or styles. The majority of RCTs included participants from North America, South America, and Asia; lacking studies from Europe and Africa. It might not be as universally transferable to other areas.

There were several other limitations in this review: the wide variety of diagnoses included; the inclusion of only certain types of people or professions, such as nurses, teachers, and peri/postmenopausal women; and patients with breast cancer, type 2 diabetes mellitus, fibromyalgia syndrome, osteoarthritis of the knee, restless leg syndrome, and primary dysfunctional uterine bleeding. The heterogeneity of interventions with different types or styles of yoga (postures, breathing, relaxation, or mediation), and potential bias were included in this systematic review.

Other threat to internal validity was study bias. Only few effects were robust against all potential bias. All of our studies claimed to have applied randomization methods; however, three RCTs failed to provide the design protocol of randomization. Some of the included studies may not have been truly randomized. Erroneous allocation concealment has been empirically revealed to be a significant source of bias in RCTs [77]. Our included studies only had a low risk or an unclear risk of detection bias without high risk detection bias. The results of meta-analysis did no changed when studies excluded high risk or unclear risk reviews on selection bias or reporting bias. The internal validity of the review appeared to be limited but acceptable.

\section{Strengths and weaknesses}

This is the first and latest systematic review and metaanalysis available on yoga for sleep quality and insomnia in women. A large number of RCTs on female population-related physiological and physiological comorbidities and risk factors in insomnia were included. There were five primary limitations of this review. First, subjective publication bias revealed in this review may have been due to selective reporting bias, which means that articles with negative findings may have not been published or poor methodological quality of including articles. We have applied Egger's Test for objective publication bias in our review. Second, the participant characteristics included in the review were heterogeneous; subgroups were included to analyze the effectiveness of different participant groups; and the small number of RCTs limited data presentation. Third, the severity of the sleep complaints and health status of participants was not considered or individually listed in each study. Baseline differences in PSQI scores were found between intervention and control groups in three studies [56, 62, 65]. This may have led to heterogeneity. The fourth limitation was the intensity, frequency, and duration of yoga interventions were heterogeneous; short term applications of less than 1 month yoga intervention were found in some studies [58, 64, 69]. Only four reviews reported long-term follow up effects, ranging from 3 months to 12 months [55-58]. Lastly, lack of safety issue evaluation including serious adverse events or nonserious events in each study.

\section{Implications for further research}

This systematic review and meta-analysis was limited by the low methodological quality of included studies. Further RCTs should ensure rigorous methodology and reporting, which would mean adequate sample size, adequate randomization, allocation concealment, 
intention-to-treat analysis, and blinding of at least outcome assessors [78]. Researchers for study interventions may need to apply a standard protocol. Adequate reporting of safety issues with yoga intervention should be discussed in future randomized controlled trials. Evidence was limited because few studies report safety-related adverse effects. Most of the included studies failed to report this aspect.

\section{Conclusion}

This systematic review and meta-analysis demonstrated that yoga intervention in women has benefits compared to non-active control conditions in term of managing sleep problems. The moderator analyses suggested that participants in the non-breast cancer subgroup or participants in the non-peri/postmenopausal subgroup were associated with greater benefits, with the longer total length of class time, the more beneficial these practices were.

\section{Abbreviations}

AEs: Adverse events; BMI: Body max index; Cl: Confidence interval; DSM4: Diagnostic and Statistical Manual of Mental Disorders, Fourth Edition criteria; DUB: Dysfunctional uterine dysfunction; ECOG-PS: Eastern Cooperative Oncology Group Performance Status; FSH: Follicle-stimulating hormone; G1 : Group 1; G2 : Group 2; G3 : Group 3; ISI: Insomnia Severity Index; IV: Inverse variance; LH: Luteinizing hormones; MD: Mean differences; OA: Osteoarthritis; OL: Onset latency; PRISMA: Preferred reporting items for systematic reviews and meta- analyses; PSQI: Pittsburgh Sleep Quality Index; RCT: Randomized controlled trial; SD: Standard deviation; SE: Sleep efficiency; SE: Standard error; SMD: Standardized mean differences; SWS: Slow- wave sleep; TST: Total sleep time; WASO: Wake time after sleep onset; XRT: Radiotherapy treatment

\section{Acknowledgements}

Not applicable.

\section{Authors' contributions}

WLW, KHC, YCP, SNY and YYC designed the study. WLW conducted the literature searches. Selection of studies and data extraction: KHC and YCP. Disagreements were resolved by discussion or arbitration by YCP and SNY. Statistical analysis: WLW, KHC, YCP, SNY and YYC. FC drafted the manuscript. WLW, KHC, YCP, SNY and YYC critically revised the manuscript and approved the final version.

\section{Funding}

The authors thank to the editor's valuable suggestion. This work was supported by the Taoyuan Armed Forces General Hospital (AFTYGH-10831 and TYAFGH-D-109026). The funder had no involvement in the design of this study and will not have any role during its execution, analyses or interpretation of data, writing the manuscript, and decision to submit the manuscript for publication.

\section{Availability of data and materials}

All data analyzed during this study are included in this published article and the original studies' publications.

\section{Ethics approval and consent to participate}

Not applicable.

\section{Consent for publication}

Not applicable.

\section{Competing interests}

The authors declare that they have no competing interests.

\section{Author details}

'Department of Psychiatry, Taoyuan Armed Forces General Hospital, Taoyuan, Taiwan. ${ }^{2}$ Department of Psychiatry, Beitou Branch, Tri-Service General Hospital, National Defense Medical Center, Taipei, Taiwan. ${ }^{3}$ Department of Psychology, Chung Yuan Christian University, Taoyuan, Taiwan.

Received: 31 July 2019 Accepted: 24 March 2020

Published online: 01 May 2020

References

1. Kessler RC, Berglund PA, Coulouvrat C, Hajak G, Roth T, Shahly V, et al. Insomnia and the performance of US workers: results from the America insomnia survey. Sleep. 2011;34:1161-71.

2. Zhang B, Wing YK. Sex differences in insomnia: a meta-analysis. Sleep. 2006; 29:85-93.

3. Kische H, Ewert R, Fietze I, Gross S, Wallaschofski H, Völzke H, et al. Sex hormones and sleep in men and women from the general population: a cross-sectional observational study. J Clin Endocrinol Metab. 2016;101: 3968-77.

4. Calhoun SL, Fernandez-Mendoza J, Vgontzas AN, Liao D, Bixler EO. Prevalence of insomnia symptoms in a general population sample of young children and preadolescents: gender effects. Sleep Med. 2014;15:91-5.

5. Kizilirmak A, Timur S, Kartal B. Insomnia in pregnancy and factors related to insomnia. Sci World J. 2012;2012:197093.

6. Kravitz HM, Ganz PA, Bromberger J, Powell LH, Sutton-Tyrrell K, Meyer PM. Sleep difficulty in women at midlife: a community survey of sleep and the menopausal transition. Menopause. 2003;10:19-28.

7. van Straten A, van der Zweerde T, Kleiboer A, Cuijpers P, Morin CM, Lancee J. Cognitive and behavioral therapies in the treatment of insomnia: a metaanalysis. Sleep Med Rev. 2018;38:3-16.

8. Riemann D, Baglioni C, Bassetti C, Bjorvatn B, Dolenc Groselj L, et al. European guideline for the diagnosis and treatment of insomnia. J Sleep Res. 2017;26(6):675-700.

9. Winkler A, Auer C, Doering BK, Rief W. Drug treatment of primary insomnia: a meta-analysis of polysomnographic randomized controlled trials. CNS Drugs. 2014;28:799-816.

10. Schroeck JL, Ford J, Conway EL, Kurtzhalts KE, Gee ME, Vollmer KA, et al. Review of safety and efficacy of sleep medicines in older adults. Clin Ther. 2016;38(11):2340-72

11. Feuerstein G. The Yoga Tradition: Its History, Literature, Philosophy, and Practice. Prescott: Hohm Press. 2008.

12. Bower JE, Garet D, Sternlieb B, Ganz PA, Irwin MR, Olmstead R, et al. Yoga for persistent fatigue in breast cancer survivors: a randomized controlled trial. Cancer. 2012;118:3766-75.

13. Zeichner SB, Zeichner RL, Gogineni K, Shatil S, loachimescu O. Cognitive behavioral therapy for insomnia, mindfulness, and yoga in patients with breast cancer with sleep disturbance: a literature review. Breast Cancer (Auckl). 2017;11:1178223417745564.

14. Buysse DJ, Reynolds CF 3rd, Monk TH, Berman SR, Kupfer DJ. The Pittsburgh sleep quality index: a new instrument for psychiatric practice and research. Psychiatry Res. 1989;28(2):193-213.

15. Hyyppa MT, Kronholm E. Quality of sleep and chronic illnesses. J Clin Epidemiol. 1989;42(7):633-8.

16. Gellman MD, Turner JR. Sleep quality. In: Encyclopedia of behavioral medicine; 2013

17. Ohayon M, Wickwire EM, Hirshkowitz M, Albert SM, Avidan A, Daly FJ, et al. National Sleep Foundation's sleep quality recommendations: first report. Sleep Health. 2017;3(1):6-19.

18. Edinger JD, Bonnet MH, Bootzin RR, Doghramji K, Dorsey CM, Espie CA, et al. Derivation of research diagnostic criteria for insomnia: report of an American Academy of Sleep Medicine work group. Sleep. 2004;27(8): 1567-96.

19. Gong H, Ni C, Shen X, Wu T, Jiang C. Yoga for prenatal depression: a systematic review and meta-analysis. BMC Psychiatry. 2015;15:14.

20. McGovern CE, Cheung C. Yoga and quality of life in women with primary dysmenorrhea: a systematic review. J Midwifery Womens Health. 2018;63: 470-82.

21. Moher D, Liberati A, Tetzlaff J, Altman DG, PRISMA Group. Reprint--preferred reporting items for systematic reviews and meta-analyses: the PRISMA statement. Phys Ther. 2009;89:873-80. 
22. Higgins JPT, Green S, Cochrane Collaboration. Cochrane handbook for systematic reviews of interventions, Cochrane Book Series, vol. xxi. Chichester; Hoboken: Wiley-Blackwell; 2008. p. 649.

23. Bastien $\mathrm{CH}$, Vallieres $\mathrm{A}$, Morin CM. Validation of the insomnia severity index as an outcome measure for insomnia research. Sleep Med. 2001;2:297-307.

24. Ibanez V, Silva J, Cauli O. A survey on sleep assessment methods. Peer J. 2018;6:e4849.

25. Buysse DJ, Ancoli-Israel S, Edinger JD, Lichstein KL, Morin CM. Recommendations for a standard research assessment of insomnia. Sleep. 2006;29(9):1155-73.

26. Administration UFaD. What is a serious adverse event? 2019. http://www. fda.gov/safety/reporting-serious-problems-fda/what-serious-adverse-event.

27. Cohen J. Statistical power analysis for the behavioral science. 2 nd ed. Hillsdale: L. Erlbaum Associates; 1988.

28. Egger M, Davey Smith G, Schneider M, Minder C. Bias in meta-analysis detected by a simple, graphical test. BMJ. 1997;315:629-34.

29. Yen CY. Effect of body balance sport training on depressive tendencies and sleep quality of female college students. J Natl Taiwan Sports Univ. 2008;19: 37-50.

30. Sun YC, Hung YC, Chang Y, Kuo SC. Effects of a prenatal yoga programme on the discomforts of pregnancy and maternal childbirth self-efficacy in Taiwan. Midwifery. 2010;26:e31-6.

31. Lengacher CA, Reich RR, Ramesar S, Alinat CB, Moscoso M, Cousin L, et al. Feasibility of the mobile mindfulness-based stress reduction for breast cancer (mMBSR(BC)) program for symptom improvement among breast cancer survivors. Psychooncology. 2018;27:524-31.

32. Carson JW, Carson KM, Porter LS, Keefe FJ, Seewaldt VL. Yoga of awareness program for menopausal symptoms in breast cancer survivors: results from a randomized trial. Support Care Cancer. 2009;17:1301-9.

33. Chattha R, Nagarathna R, Padmalatha V, Nagendra HR. Effect of yoga on cognitive functions in climacteric syndrome: a randomised control study. BJOG. 2008;115:991-1000.

34. Vadiraja SH, Rao MR, Nagendra RH, Nagarathna R, Rekha M, Vanitha N, et al. Effects of yoga on symptom management in breast cancer patients: a randomized controlled trial. Int J Yoga. 2009;2:73-9.

35. Witek Janusek L, Tell D, Mathews HL. Mindfulness based stress reduction provides psychological benefit and restores immune function of women newly diagnosed with breast cancer: a randomized trial with active control. Brain Behav Immun. 2019;80:358-73.

36. Lotzke D, Wiedemann F, Rodrigues Recchia D, Ostermann T, Sattler D, Ettl J, et al. lyengar-yoga compared to exercise as a therapeutic intervention during (neo)adjuvant therapy in women with stage I-III breast cancer: health-related quality of life, mindfulness, spirituality, life satisfaction, and cancer-related fatigue. Evid Based Complement Alternat Med. 2016;2016: 5931816.

37. Ghaffarilaleh G, Ghaffarilaleh V, Sanamno Z, Kamalifard M. Yoga positively affected depression and blood pressure in women with premenstrual syndrome in a randomized controlled clinical trial. Complement Ther Clin Pract. 2019;34:87-92.

38. Mustian KM, Sprod LK, Janelsins M, Peppone L, Palesh OG, Chandwani K, et al. Multicenter, randomized controlled trial of yoga for sleep quality among cancer survivors. J Clin Oncol. 2013;31:3233-41.

39. Kohn M, Persson Lundholm U, Bryngelsson IL, Anderzén-Carlsson A, Westerdahl E. Medical yoga for patients with stress-related symptoms and diagnoses in primary health care: a randomized controlled trial. Evid Based Complement Alternat Med. 2013;2013:215348.

40. Sakuma Y, Sasaki-Otomaru A, Ishida S, Kanoya Y, Arakawa C, Mochizuki Y, et al. Effect of a home-based simple yoga program in child-care workers: a randomized controlled trial. J Altern Complement Med. 2012;18:769-76.

41. Chen KM, Chen MH, Chao HC, Hung HM, Lin HS, Li CH. Sleep quality, depression state, and health status of older adults after silver yoga exercises: cluster randomized trial. Int J Nurs Stud. 2009;46:154-63.

42. Jain M, Tripathy PR, Manik R, Tripathy S, Behera B, Barman A. Short term effect of yoga asana - an adjunct therapy to conventional treatment in frozen shoulder. J Ayurveda Integr Med. 2019.

43. Carson JW, Carson KM, Jones KD, Bennett RM, Wright CL, Mist SD. A pilot randomized controlled trial of the yoga of awareness program in the management of fibromyalgia. Pain. 2010;151:530-9.

44. Zhang JX, Liu XH, Xie XH, Zhao D, Shan MS, Zhang XL, et al. Mindfulnessbased stress reduction for chronic insomnia in adults older than 75 years: a randomized, controlled, single-blind clinical trial. Explore. 2015;11:180-5.
45. Yurtkuran M, Alp A, Yurtkuran M, Dilek K. A modified yoga-based exercise program in hemodialysis patients: a randomized controlled study. Complement Ther Med. 2007;15:164-71.

46. Ward L, Stebbings S, Athens J, Cherkin D, David Baxter G. Yoga for the management of pain and sleep in rheumatoid arthritis: a pilot randomized controlled trial. Musculoskeletal Care. 2018;16:39-47.

47. Field T, Diego M, Delgado J, Medina L. Tai chi/yoga reduces prenatal depression, anxiety and sleep disturbances. Complement Ther Clin Pract. 2013;19:6-10

48. Andersen SR, Würtzen H, Steding-Jessen M, Christensen J, Andersen KK, Flyger $\mathrm{H}$, et al. Effect of mindfulness-based stress reduction on sleep quality: results of a randomized trial among Danish breast cancer patients. Acta Oncol. 2013;52:336-44.

49. Vardar Yagli N, Şener G, Arıkan H, Sağlam M, Inal İnce D, Savcı S, et al. Do yoga and aerobic exercise training have impact on functional capacity, fatigue, peripheral muscle strength, and quality of life in breast cancer survivors? Integr Cancer Ther. 2015;14:125-32.

50. Guthrie KA, Larson JC, Ensrud KE, Anderson GL, Carpenter JS, Freeman EW, et al. Effects of pharmacologic and nonpharmacologic interventions on insomnia symptoms and self-reported sleep quality in women with hot flashes: a pooled analysis of individual participant data from four MsFLASH trials. Sleep. 2018;41(1). https://doi.org/10.1093/sleep/zsx190.

51. Reed SD, Guthrie KA, Newton KM, Anderson GL, Booth-LaForce C, Caan B, et al. Menopausal quality of life: RCT of yoga, exercise, and omega-3 supplements. Am J Obstet Gynecol. 2014;210:244.e1-11.

52. Ashrafinia F, Mirmohammadali M, Rajabi H, Kazemnejad A, Sadeghniiathaghighi K, Amelvalizadeh M, et al. The effects of Pilates exercise on sleep quality in postpartum women. J Bodyw Mov Ther. 2014;18:190-9.

53. Aibar-Almazána A, Hita-Contreras F, Cruz-Díaz D, de la Torre-Cruz M, Jiménez-García JD, Martínez-Amat A. Effects of Pilates training on sleep quality, anxiety, depression and fatigue in postmenopausal women: a randomized controlled trial. Maturitas. 2019;124:62-7.

54. Danhauer SC, Mihalko SL, Russell GB, Campbell CR, Felder L, Daley K, et al. Restorative yoga for women with breast cancer: findings from a randomized pilot study. Psychooncology. 2009;18:360-8.

55. Chandwani KD, Thornton B, Perkins GH, Arun B, Raghuram NV, Nagendra HR, et al. Yoga improves quality of life and benefit finding in women undergoing radiotherapy for breast cancer. J Soc Integr Oncol. 2010;8:43-55.

56. Kiecolt-Glaser JK, Barrow J, Makambi K, Sheppard V, Wallington SF, Martin C, et al. Yoga's impact on inflammation, mood, and fatigue in breast cancer survivors: a randomized controlled trial. J Clin Oncol. 2014;32:1040-9.

57. Ratcliff CG, Milbury K, Chandwani KD, Chaoul A, Perkins G, Nagarathna R, et al. Examining mediators and moderators of yoga for women with breast cancer undergoing radiotherapy. Integr Cancer Ther. 2016;15:250-62.

58. Chaoul A, Milbury K, Spelman A, Basen-Engquist K, Hall MH, Wei Q, et al. Randomized trial of Tibetan yoga in patients with breast cancer undergoing chemotherapy. Cancer. 2018;124:36-45.

59. Porter LS, et al., Feasibility of a mindful yoga program for women with metastatic breast cancer: results of a randomized pilot study. Support Care Cancer, 2019;27(11):4307-16.

60. Elavsky S, McAuley E. Lack of perceived sleep improvement after 4-month structured exercise programs. Menopause. 2007;14:535-40.

61. Afonso RF, Hachul H, Kozasa EH, Oliveira Dde S, Goto V, Rodrigues D, et al. Yoga decreases insomnia in postmenopausal women: a randomized clinical trial. Menopause. 2012;19:186-93.

62. Newton KM, Reed SD, Guthrie KA, Sherman KJ, Booth-LaForce C, Caan B, et al. Efficacy of yoga for vasomotor symptoms: a randomized controlled trial. Menopause. 2014;21:339-46.

63. Buchanan DT, Landis CA, Hohensee C, Guthrie KA, Otte JL, Paudel M, et al. Effects of yoga and aerobic exercise on actigraphic sleep parameters in menopausal women with hot flashes. J Clin Sleep Med. 2017;13:11-8.

64. Ide MR, Laurindo LMM, Rodrigues-Junior AL, Tanaka C. Effect of aquaticrespiratory exercise-based program in patients with fibromyalgia. Int J Rheum Dis. 2008;11:131-40.

65. Innes KE, Selfe TK. The effects of a gentle yoga program on sleep, mood, and blood pressure in older women with restless legs syndrome (RLS): a preliminary randomized controlled trial. Evid Based Complement Alternat Med. 2012;2012:294058.

66. Cheung C, Wyman JF, Resnick B, Savik K. Yoga for managing knee osteoarthritis in older women: a pilot randomized controlled trial. BMC Complement Altern Med. 2014;14:160. 
67. Fang $R, L i X$. A regular yoga intervention for staff nurse sleep quality and work stress: a randomised controlled trial. J Clin Nurs. 2015;24:3374-9.

68. Ebrahimi M, Guilan-Nejad TN, Pordanjani AF. Effect of yoga and aerobics exercise on sleep quality in women with type 2 diabetes: a randomized controlled trial. Sleep Sci. 2017;10:68-72.

69. Rao M, Metri KG, Raghuram N, Hongasandra NR. Effects of mind sound resonance technique (yogic relaxation) on psychological states, sleep quality, and cognitive functions in female teachers: a randomized, controlled trial. Adv Mind Body Med. 2017;31:4-9.

70. Nalgirkar SP, Vinchurkar SA, Saoji AA, Mohanty S. Yoga as a therapeutic intervention in the management of dysfunctional uterine bleeding: a controlled pilot study. J Midlife Health. 2018;9(1):8-13.

71. Taylor TR, Barrow J, Makambi K, Sheppard V, Wallington SF, Martin C, et al. A restorative yoga intervention for African-American breast cancer survivors: a pilot study. J Racial Ethn Health Disparities. 2018:5:62-72.

72. Wang X, Li P, Pan C, Dai L, Wu Y, Deng Y. The effect of mind-body therapies on insomnia: a systematic review and meta-analysis. Evid Based Complement Alternat Med. 2019;2019:9359807.

73. Rubio-Arias JA, Marín-Cascales E, Ramos-Campo DJ, Hernandez AV, PérezLópez FR. Effect of exercise on sleep quality and insomnia in middle-aged women: a systematic review and meta-analysis of randomized controlled trials. Maturitas. 2017:100:49-56.

74. Cramer H, Peng W, Lauche R. Yoga for menopausal symptoms-a systematic review and meta-analysis. Maturitas. 2018;109:13-25.

75. Tang MF, Chiu HY, Xu X, Kwok JY, Cheung DST, Chen CY, et al. Walking is more effective than yoga at reducing sleep disturbance in cancer patients: a systematic review and meta-analysis of randomized controlled trials. Sleep Med Rev. 2019:47:1-8.

76. Du S, Dong J, Zhang H, Jin S, Xu G, Liu Z, et al. Taichi exercise for self-rated sleep quality in older people: a systematic review and meta-analysis. Int J Nurs Stud. 2015;52(1):368-79.

77. Schulz KF, Chalmers I, Hayes RJ, Altman DG. Empirical evidence of bias. Dimensions of methodological quality associated with estimates of treatment effects in controlled trials. JAMA. 1995;273:408-12.

78. Schulz KF, Altman DG, Moher D. CONSORT 2010 statement: updated guidelines for reporting parallel group randomised trials. J Pharmacol Pharmacother. 2010;1:100-7.

\section{Publisher's Note}

Springer Nature remains neutral with regard to jurisdictional claims in published maps and institutional affiliations.

Ready to submit your research? Choose BMC and benefit from:

- fast, convenient online submission

- thorough peer review by experienced researchers in your field

- rapid publication on acceptance

- support for research data, including large and complex data types

- gold Open Access which fosters wider collaboration and increased citations

- maximum visibility for your research: over $100 \mathrm{M}$ website views per year

At $\mathrm{BMC}$, research is always in progress.

Learn more biomedcentral.com/submissions 